Article

\title{
Precipitation Trends and Alteration in Wei River Basin: Implication for Water Resources Management in the Transitional Zone between Plain and Loess Plateau, China
}

\author{
Ci Li ${ }^{1}$, Hongbo Zhang ${ }^{1,2, * \mathbb{D}}$, Xinghui Gong ${ }^{1,2}$, Xiaowei Wei ${ }^{1}$ and Jiantao Yang ${ }^{1}$ \\ 1 School of Environmental Science and Engineering, Chang' an University, Xi'an 710054, China; \\ 2017229012@chd.edu.cn (C.L.); gongxinghui@chd.edu.cn (X.G.); 2017129014@chd.edu.cn (X.W.); \\ 2017129011@chd.edu.cn (J.Y.) \\ 2 Key Laboratory of Subsurface Hydrology and Ecological Effect in Arid Region, Ministry of Education, \\ Chang'an University, Xi'an 710054, China \\ * Correspondence: hbzhang@chd.edu.cn; Tel.: +86-029-8233-99959
}

Received: 7 October 2019; Accepted: 12 November 2019; Published: 16 November 2019

check for updates

\begin{abstract}
Precipitation plays a critical role in water resources management, and trend changes and alterations thereof are crucial to regional or basin water security, disaster prevention, and ecological restoration under a changing environment. In order to explore the implications of precipitation variation for water resources management, taking the Wei River Basin (a transitional zone between the Guanzhong Plain and Loess Plateau) as an example, this paper proposes an index system, namely the index of precipitation alteration (IPA), to evaluate changes in precipitation and investigate their potential influence on water resources management. The system includes 17 indicators gained from observed daily rainfall, involving some structural precipitation indicators describing the precipitation patterns and some functional precipitation indicators influencing utilization of watershed water resources. Non-parametric Mann-Kendall (MK) statistical test is employed to identify the IPA trend change, and range of variability approach is used to evaluate the variation of IPA. The analysis results in Wei River Basin show that IPA varies with different spatial and temporal distributions. Overall, although the annual total precipitation declined in the study area, the frequency of extreme events was increased during 1955-2012. In the face of severe climate change patterns, it is necessary to establish the precipitation index to evaluate the change of precipitation and to provide useful information for future precipitation assessments.
\end{abstract}

Keywords: indicator of precipitation alteration; Mann-Kendall trend tests; precipitation variability; transitional zone; Wei River Basin

\section{Introduction}

Climate change has a significant influence on the ecosystem and human wellbeing [1], and is causing a universal redistribution of life and changing the spatiotemporal land use/land cover (LULC) on Earth [2] at present. Precipitation is a key parameter related to major climate impacts, and it is necessary to explore the spatiotemporal patterns of precipitation change, as the structural and functional precipitation indexes are leading LULC changes and are related to climate change impacts such as droughts and floods. These changes and impacts will further affect ecosystem function and the social development of human beings. The fifth assessment report of the intergovernmental panel on climate change published by the United Nations proposed that the global land and ocean surface temperature has increased by an average of $0.85{ }^{\circ} \mathrm{C}$ per year [3] since the middle of the 19th century, 
which has brought about global climate change and variation in water resources. In previous studies, many scholars have suggested that the structure of global precipitation has changed greatly over time and space. For example, Longobardi et al. [4] identified that seasonal differences had reduced over a large portion of the Italian peninsula by analyzing the precipitation concentration index trend. Chen et al. [5] demonstrated that heavy rainfall event frequency is the major contributor to total rainfall variability by studying the structure of precipitation in eastern China. Huang et al. [6] emphasized that drought risks vary across different areas of the Wei River Basin along with differences of precipitation patterns. A study on global-warming-induced precipitation variability by Karl and Knight [7] showed that the extreme and heavy events in the U.S. have increased, and moderate events have presented a decreasing trend in recent years [8]. Research published by Pfahl et al. [9] showed that extreme precipitation events could increase continuously during the 21st century, and this trend might continue into the future. Zhao et al. [10] proposed that a daily precipitation change was evident in northwest China and identified uneven distribution in various regions. Understanding precipitation pattern changes and their influences on watershed water resource utilization is important; it can help us to study regional water cycles in a changing environment and to make informed decisions about climate change. Through the link between precipitation and climate change impacts, negative influences can be forecasted via detected change in precipitation and warned for early.

Based on these climate changes, some researchers have focused on the indicators of precipitation characteristic changes. For example, climate change indexes (CCI) [11] were proposed by Michele for detecting climate change, and the standardized precipitation index (SPI) [12] has been used to demonstrate drought regimes and the occurrence of flood spells. Changes in these indicators are closely related to human life and security, and understanding the changes is important to enable scientific decisions relating to climate change. However, disadvantages to these indicators exist; the CCI, which includes 27 core indexes to explore climate change, mainly focuses on extreme changes of precipitation value, and it is not suitable for areas where rainfall is insufficient. The SPI only makes specific analysis of drought or flood situations in an area, and does not describe precipitation structural changes or other functional demand.

Many experts and scholars have mentioned indicators in their articles. For example, Chen et al. [13] studied "fixed threshold" indexes, "station-related threshold" indexes, and "non-threshold" indexes of precipitation in Yunnan province. Rahmani et al. [14] focused on extreme precipitation indexes for assessing climate change in the central United States. Zhang et al. [15] analyzed changes in "max 1-day precipitation amount", "max 5-day precipitation amount", "simple daily intensity index", "number of heavy precipitation days", "consecutive dry days", "consecutive wet days", "very wet days", "extremely wet days", "wet days", and "annual total wet-day precipitation" in southeastern Tibet, China. Zhang et al. [16] applied 27 core indexes of Climate Change Detection Monitoring and Indices (ETCCDMI) to explain the climate change trend in the Middle East. Griffiths et al. [17] studied the variations of "frost days", "extreme temperature range", "growing season length", "heat wave duration index", "warm nights", "heavy precipitation days", "consecutive dry days", "maximum 5-day precipitation total", "simple daily intensity index" and "very wet days" in the northeast United States. Li et al. [18] focused on nine indicators of change, including "heavy rainfall threshold", "greatest 5-day total rainfall", "simple daily rainfall intensity", "longest dry period", "heavy rainfall days", "hot-day threshold", "cold-night threshold", "number of frost days $\mathrm{T}_{\min }<0{ }^{\circ} \mathrm{C}^{\prime}$, and "longest heatwave" on the Loess Plateau. However, the indexes they discussed are not fully applicable to the Wei River Basin located in the transitional zone between Guanzhong Plain and the Loess Plateau. Generally speaking, structural indexes describing precipitation magnitude, duration, frequency, intensity, distribution, and extreme events have advantages in predicting precipitation patterns; however, they are not closely connected with human beings' requirements and cannot provide direct guidance for human activities. Functional indexes generally have a specific object orientation and it is difficult to implement a systematic consideration. The precipitation index used in this study, the index of precipitation alteration (IPA), should be used to conduct multi-scale and multi-angle analyses of precipitation 
to explore precipitation changes in a more comprehensive way, including structural or functional precipitation indexes.

The Wei River Basin covers the transitional zone between plain and loess plateau in western China, and is an ecologically vulnerable area and economic development zone in the new Silk Road economic belt, heavily influenced by climate change and human activities. Precipitation plays an important role in basin water utilization and disaster and ecological safety, and any change will directly influence the socioeconomic development in this basin. Selecting this basin to study the precipitation alteration was therefore relevant to regional water resources management. In constructing the IPA of the Wei River Basin, several indicators were extracted from daily precipitation data series, which were introduced to demonstrate the relationships between precipitation and the hydrological cycle and human society. We then analyzed the variation of the precipitation sequence using statistical methods to explore the evolution law of precipitation and the potential impact of climate change on water resources and ecological security in the Wei River Basin.

\section{Study Area and Data}

\subsection{Study Area}

The Wei River originates from the Niaoshu Mountain in Weiyuan County, Gansu Province, China, and flows through the Loess Plateau in east Gansu, Tianshui Basin, and Baoji Canyon, and enters the Guanzhong Plain. It then flows into the Yellow River in Tongguan County, which is approximately $818 \mathrm{~km}$ long with a basin area of $134,800 \mathrm{~km}^{2}$ (Figure 1). As the major tributary of the Yellow River, meteorological and hydrological changes in the basin directly affect the development of water resources in the Yellow River Basin. The Wei River Basin is located in a continental monsoon climate zone, and its annual precipitation is approximately $572 \mathrm{~mm}, 60 \%$ of which occurs during the flood season. Spatially, the precipitation in the basin has a decreasing trend from the south to north and from the valley area to the Loess Plateau. Correspondingly, river runoff and vegetation cover have similar non-uniform distributions in space and time.

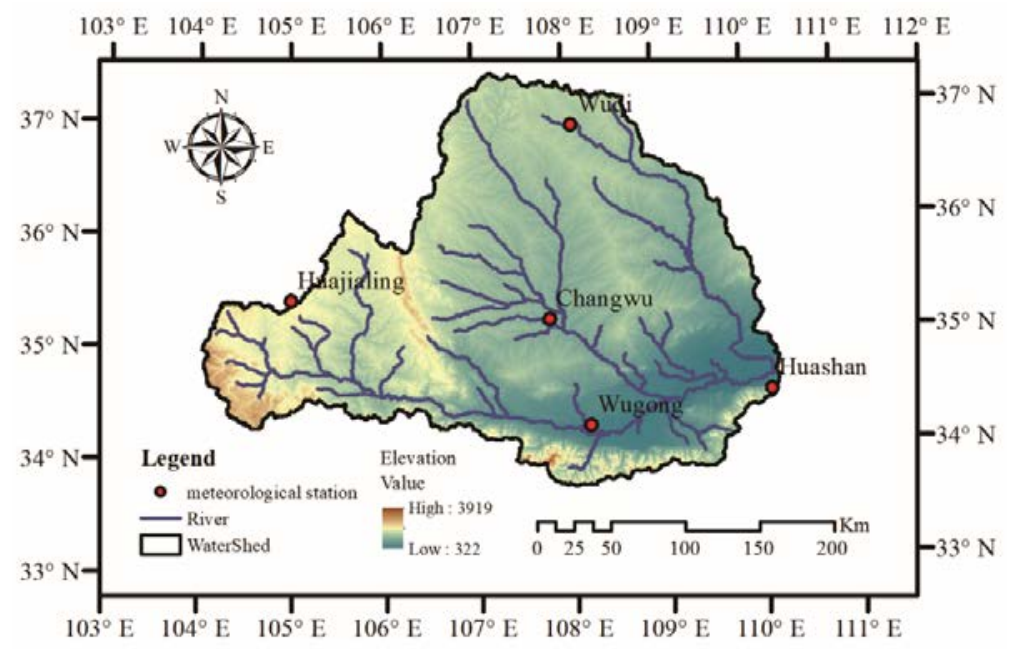

Figure 1. The basin and the locations of meteorological stations.

The Wei River Basin is one of most ecologically fragile zones in China, in which natural disasters occur frequently as a result of extreme events. Severe drought or flood disaster losses often have great impacts on sustainable agricultural development [19] and the regional economy [20]. It should be mentioned that climate change has led to the decrease of precipitation, and extreme drought events [21] are now occurring more frequently than ever, which has caused eco-environmental problems such as dry season cut-off, river channel sedimentation, and ecological environment degradation, which are becoming increasingly prominent under the influence of regional development. In recent years, 
the government has paid much attention to this issue [22], and the water volume of the Wei River and the ecological environment along the river have shown a significant improvement. However, the threat has not been eliminated in the face of continuous climate change. It is thus particularly urgent to address the challenge of climate change by analyzing the precipitation-change-induced hydrological changes that may have an impact on human society in the Wei River Basin.

\subsection{Data}

Daily precipitation data from five meteorological stations (Huajialing, Wugong, Huashan, Changwu, and Wuqi, as shown in Figure 1) in the Wei River Basin were employed in this study. Among the stations, Huajialing, Wugong, and Huashan Stations are located in the upper, middle, and lower reaches of the Wei River Basin, respectively, allowing representation of the precipitation changes in the flow direction of the Wei River. Wugong, Changwu, and Wuqi Stations were selected to represent the spatial heterogeneity of precipitation change over different landforms from the plain to the loess plateau. Through the precipitation data series of the stations, the spatial variation of the precipitation and its response to multiple geomorphic types in the Wei River Basin was identified. The research offers a valuable contribution to ongoing research in the field.

The daily precipitation data from the stations were provided by the National Climate Center of the China Meteorological Administration (http://data.cma.cn/), including data from Huajialing Station (1955-2016), Wugong Station (1955-2016), Huashan Station (1953-2012), Changwu Station (1955-2016), and Wuqi Station (1955-2016).

\section{Methodology}

\subsection{Mann-Kendall Trend Test}

The Mann-Kendall method (MK), proposed by Mann [23] and Kendall [24], is a common non-parametric test method which is often used to evaluate the significance of monotone trends in time series. The advantage of this method is that it does not assume any distribution of data and is not disturbed by other parameters. To date, the non-parametric MK statistical test has been widely used to assess the significance of trends in hydrometeorological time series. In this study, the MK method was employed to detect the trend change of different IPAs. At the $95 \%$ significance level, $\alpha$ was 0.05 , and the corresponding $\mathrm{Z}_{1-\alpha / 2}$ statistic was equal to 1.96 . When $|\mathrm{Z}| \leq 1.96$, the null hypothesis $\mathrm{H}_{0}$ was accepted, indicating that there was no obvious trend. The trend was significant at the $95 \%$ confidence level if $|Z| \geq 1$.96. In addition, a positive $Z$ statistic indicates that a sequence has an increasing trend, while a negative $Z$ reflects a declining trend [25].

\subsection{Concentration Index}

\subsubsection{Monthly Precipitation Concentration Index}

The monthly precipitation concentration index (PCI) is often employed to evaluate rainfall concentration to provide information on rainfall variability [26] and is used to assess the heterogeneity of monthly rainfall. The index is defined as follows:

$$
P C I=100 \times \frac{\left(\sum_{i=1}^{12} p_{i}^{2}\right)}{\left(\sum_{i=1}^{12} p_{i}\right)^{2}}
$$

where $p_{i}$ is the monthly precipitation in the $i$ th month. According to Equation (1) and referring to the evaluation criteria of PCI, as described by Lu et al. [27], if the annual rainfall is concentrated in a single month, the value of PCI will be equal to the maximum of 100. If the annual rainfall is uniformly distributed throughout 12 months in the same year, the PCI values will be less than 10 . Values between 11 and 15 denote a seasonal distribution and a moderate precipitation concentration. Values ranging 
from 16 to 20 indicate that the monthly rainfall distribution is irregular and that more rain falls in a few particular months. If the value more than 20 , the precipitation distribution throughout the year is strongly irregular. The PCI values in this study were calculated using the average monthly precipitation during the selected period.

\subsubsection{Daily Precipitation Concentration Index}

In a year, low rainfall days occur often and heavy rainfall days do not necessarily occur at all. However, the precipitation occurring in the few heavy rainfall days has a considerable weight, constituting the majority percentage in the total precipitation amount. For this reason, the concentration index (CI) proposed by Martin-Vide [28] is generally employed to evaluate the variations in the proportion of daily precipitation and to calculate the contribution of daily rainfall events to the total amount. In the calculation of $\mathrm{CI}$, the relationship between the cumulative percentage contribution of precipitation amount $Y$ and the cumulative percentage of wet days $X$ is used to calculate the $C I$, determining the percentage impact of the daily precipitation in different classes or different magnitudes of daily precipitation. In this study, a wet day is defined as a day with rainfall exceeding $0.1 \mathrm{~mm}$, and $1 \mathrm{~mm}$ of precipitation was employed as the precipitation interval to classify the precipitation levels or "precipitation limits". The irregular distribution of rainfall was determined by calculating the percentage of rainfall falling in each class. The daily precipitation percentage of different classes to total precipitation was obtained using a negative exponential curve or normalized precipitation curve. The calculation steps were as follows:

Step 1.Classify the daily rainfall by class limits ( $1 \mathrm{~mm}$ class interval used in this paper);

Step 2. Count the number of wet days in each class $(i=1,2 \ldots N)$ and calculate the amount of precipitation falling in each class;

Step 3. Compute the cumulative sum of the output items in Step 2;

Step 4. Based on the results of Step 3, calculating the accumulated percentage of wet days $(X)$ and the corresponding accumulated percentage of precipitation $(Y)$;

Step 5. Derive the exponential curve of $X$ versus $Y$. The curve to match the empirical pairs of value ( $X i$, $Y$ i) is defined as:

$$
Y=a \times X \times \exp (b X)
$$

where $a$ and $b$ are regression coefficients, which can be determined by the least-squares method.

The daily precipitation concentration index is defined as.

$$
C I=\frac{S}{5000}
$$

where $S$ is the area enclosed by the bisector of the quadrant and the polygonal line, calculated by Equation (4).

$$
S=5000-A
$$

where $A$ is the definite integral between 0 and 100 of the curves, representing the area under the curve, and can be obtained using Equation (5).

$$
A=\int_{0}^{100} \frac{a}{b} e^{b x}\left(x-\frac{1}{b}\right) d x
$$

The CI value is the fraction of $\mathrm{S}$ in the area of the lower triangular area defined by the perfect distribution $\left(45^{\circ}\right)$ line, and it varies from 0 to 1 . According to a previous study [29], CI $<0.55$ is low, $0.55<\mathrm{CI}<0.61$ is moderate, and $\mathrm{CI}>0.61$ is high. A greater $\mathrm{CI}$ value indicates a higher concentration degree. CI values of more than 0.61 reflect that more than $70 \%$ of the total precipitation amount fell on $25 \%$ of heavy precipitation days. 
Martin-Vide [10] concluded that a CI value of up to 0.7 indicated that more than $80 \%$ of all precipitation fell on $25 \%$ of heavy precipitation days.

\section{IPA Index System}

Precipitation changes are critical to human development under climate change. It has thus been suggested that precipitation indexes should not only reflect changes in precipitation itself, but should also include more referential information associated with human demand. To this end, the indicator of precipitation alteration (IPA) was proposed in this study. The IPA is a precipitation index describing precipitation change, the purpose of which is to demonstrate the relationships between precipitation and hydrological cycles and human society, including structural and functional precipitation indexes. Therein, the structural precipitation index describes the general changes in precipitation, identifying what has happened to the precipitation pattern. The functional precipitation index describes the changes in precipitation associated with human development, revealing what impact precipitation changes will have. In addition, the IPA can be used to forecast or give early warning of the influence of climate change via the detected change in precipitation, in term of the link of precipitation and climate change impacts such as drought, floods, and LULC changes, and further provide more references to mitigate the negative impact of climatic changes.

\subsection{Primary Selection of Precipitation Index}

There are many precipitation indexes used worldwide in research on climate change, regional water resources management, ecological protection, and disaster prevention. Some of these are employed to reflect the variation characteristics of precipitation itself, namely the precipitation structural index (PSI), and some focus on the influence of precipitation changes on human water use, namely the precipitation functional index (PFI). Of course, the two are not entirely distinguishable and part of the PFI is also regarded as part of the PSI, which called the coupling precipitation index (CPI). In this study, many indexes recorded in previous studies reflecting precipitation characteristics were collected as a preliminary precipitation index set.

Group 1, describing average precipitation regime, included 17 indicators, i.e., total annual rainfall (PRCPTOT), total rainfall in season ( $\left.T R_{\text {Spring }}, \mathrm{TR}_{\text {Summer }}, \mathrm{TR}_{\text {Autumn }}, \mathrm{T} \mathrm{R}_{\text {Winter }}\right)$, monthly rainfall $\left(\mathrm{R}_{\mathrm{Jan}}\right.$, $\left.\mathrm{R}_{\mathrm{Feb}}, \mathrm{R}_{\mathrm{Mar}}, \mathrm{R}_{\mathrm{Apr}}, \mathrm{R}_{\mathrm{May}}, \mathrm{R}_{\mathrm{Jun}}, \mathrm{R}_{\mathrm{Jul}}, \mathrm{R}_{\mathrm{Aug}}, \mathrm{R}_{\mathrm{Sep}}, \mathrm{R}_{\mathrm{Oct}}, \mathrm{R}_{\mathrm{Nov}}, \mathrm{R}_{\mathrm{Dec}}\right)$, total rainfall in flood and dry seasons (Flood Season and Dry Season), simple daily precipitation intensity index (SDII), R10 mm (R10), R25 $\mathrm{mm}$ (R25), R50 $\mathrm{mm}$ (R50), and R100 $\mathrm{mm}$ (R100). SDII is computed by taking the sum of precipitation across wet days (days with $>1 \mathrm{~mm}$ of precipitation) and dividing that by the number of wet days in the period. R10 mm, R25 mm, R50 mm, and R100 mm represent days with a daily precipitation amount $\geq 10 \mathrm{~mm}, 25 \mathrm{~mm}, 50 \mathrm{~mm}$, and $100 \mathrm{~mm}$, respectively.

Group 2, described extreme behavior of precipitation such as persistence, magnitude, and intensity, includes maximum 1-day (Rx1day), 3-day (Rx3day), 5-day (Rx5day), 7-day (Rx7day), and 30-day (Rx30day) precipitation, R95pTOT, and R99pTOT. R95pTOT presents the fraction of the sum of precipitation on days where daily precipitation exceeded the 95th percentile of daily precipitation in the base period, and R99pTOT demonstrates the fraction of the sum of precipitation on days where daily precipitation exceeded the 99th percentile of daily precipitation in the base period.

Group 3 described the duration characteristics of precipitation, i.e., consecutive wet days (CWD), consecutive dry days (CDD), and number of dry days (NDD). The CDD is the maximum number of consecutive days with precipitation $<1 \mathrm{~mm}$, and CWD is the maximum number of consecutive days with precipitation $\geq 1 \mathrm{~mm}$.

Group 4 described the distribution of precipitation, including mean, variance, (monthly) precipitation concentration index (PCI), and concentration index (CI). The $\mathrm{PCI}$ is used to investigate monthly rainfall heterogeneity on an annual scale, varying from 8 to 100, which explains the degree of precipitation concentration during a given year. The $\mathrm{CI}$ is used to evaluate the contribution of the highest daily precipitation to the total amount. 
To sum up, 36 indicators were identified. These indicators were found to include many important structural and functional precipitation indicators, some of which have often been used to explore the impacts of climate change on regional hydrological cycles, terrestrial ecosystem security, and water resource utilization through trend or variation analysis. However, there were too many indicators with significant overlap among them, so the preliminary index set was simplified.

\subsection{Establishment of IPA Index}

To simplify the index, the maximal information coefficient (MIC) was used for the establishment of IPA. The MIC is a statistical method used to measure the strength of linear or non-linear associations among variables [30]. The value of the coefficient is between $0-1$. The dependence between the two variables is significant for MIC values larger than or equal to 0.35 [31]. In this study, Python software was used to simplify the IPA indexes.

The R100 series statistical analysis returned too many zeroes and was therefore not selected for the MIC procedure. The correlation coefficients were calculated between 35 primary indicators, and the results of five stations were presented as heat maps (Figure 2).

As can be seen from the above heat map, the coefficients of precipitation indicators were significantly different across the five stations. For example, at Huajialing Station, the indicators with the highest correlation with other indicators were Flood Season, PRCPTOT, and TR $\mathrm{R}_{\text {Summer. }}$ Among all indexes, there were 12 pairs of indicators with correlation coefficients of $>0.75,19$ pairs of indicators with correlation coefficients between 0.6 and 0.75 , and 4 pairs of monthly precipitation indexes with correlation coefficients between 0.35 and 0.6. Specific results are shown in Figure 3.

At Wugong Station, the indicators with the highest correlations with other indicators were different from those at Huajialing Station: Rx7day, Rx5day, Rx3day, Rx30day, Rx1day, Flood Season, and R99pTOT. Among all indexes, there were 11 pairs of indexes with correlation coefficients of $>0.75,16$ pairs of indexes with correlation coefficients between 0.6 and 0.75 , and 5 pairs of monthly precipitation indexes with correlation coefficients between 0.35 and 0.6 . Specific results are shown in Figure 4.

At Huashan Station, the indicators with the highest correlation with other indicators were PRCPTOT, Flood Season, Rx30day, Rx7day, Rx5day, TR Summer, $_{\text {, }}$ and R99pTOT. Among all indexes, there were 7 pairs of indexes with correlation coefficients of $>0.75,21$ pairs indexes with correlation coefficients between 0.6 and 0.75 , and 4 pairs of monthly precipitation indexes with correlation coefficients between 0.35 and 0.6. Specific results are shown in Figure 5.

At Changwu Station, the indicators with the highest correlation with other indicators were Flood Season, PRCPTOT, Rx30day, and Rx7day. Among all indexes, there were 6 pairs of indexes with correlation coefficients of $>0.75,20$ pairs of indexes with correlation coefficients between 0.6 and 0.75 , and 4 pairs of monthly precipitation indexes with correlation coefficients between 0.35 and 0.6 . Specific results are shown in Figure 6.

At Wuqi Station, the indicators with the highest correlation with other indicators were different from those at the other stations, including $\mathrm{TR}_{\text {Summer}}, \mathrm{TR}_{\text {Winter }}$, Flood Season, $\mathrm{TR}_{\text {Autumn, }}$ dry season, $\mathrm{Rx} 3 \mathrm{day}$, and $\mathrm{R}_{\mathrm{Jul}}$. Among all indexes, there were 5 pairs of indexes with correlation coefficient of $0.75^{+}, 36$ pairs of indexes with correlation coefficients between 0.6 and 0.75 , and 30 pairs of monthly precipitation indexes with correlation coefficients between 0.35 and 0.6 . Specific results are shown in Figure 7. 


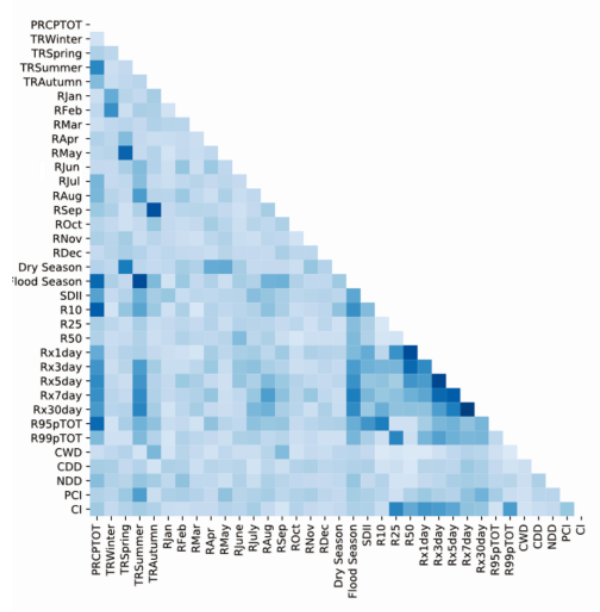

(a) Huajialing

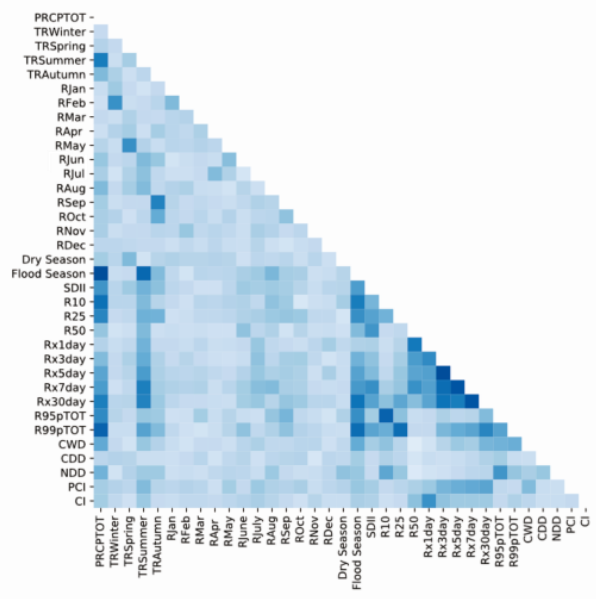

(c) Huashan

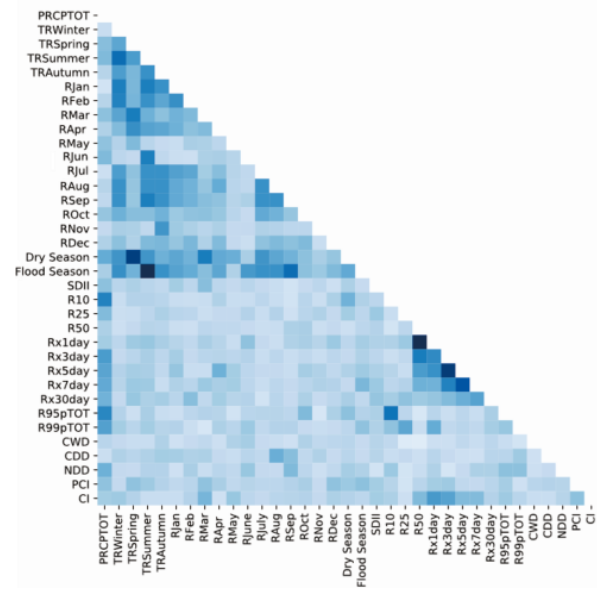

(e) Wuqi

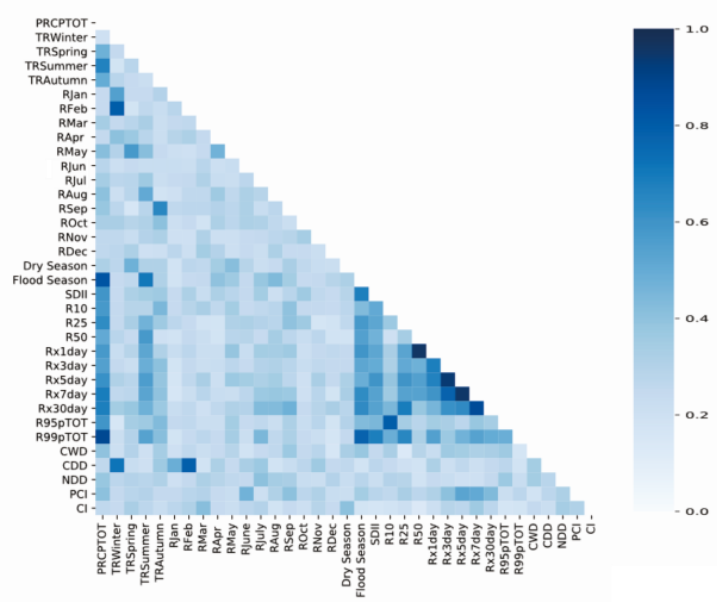

(b) Wugong

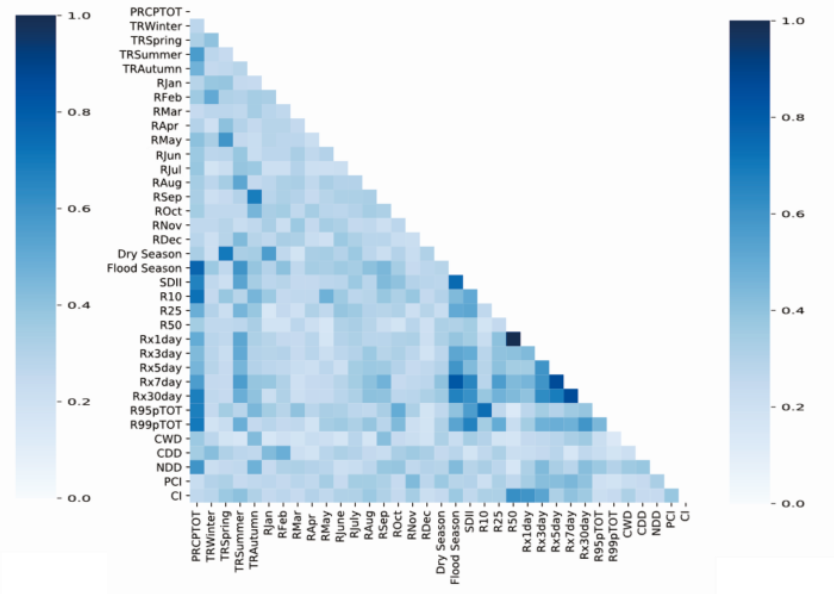

(d) Changwu

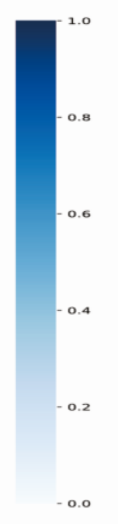

Figure 2. The heat map of correlation coefficients obtained via maximal information coefficient (MIC) across five stations: (a) Huajialing, (b) Wugong, (c) Huashan, (d) Changwu, and (e) Wuqi. 


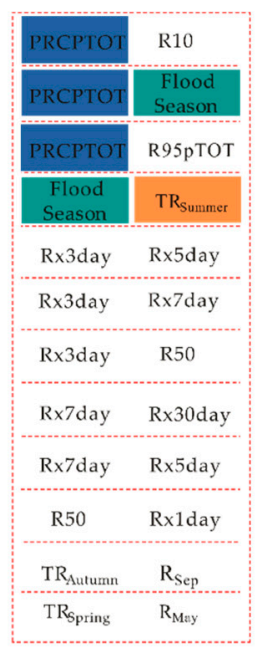

Correlation Coefficient $>0.75$

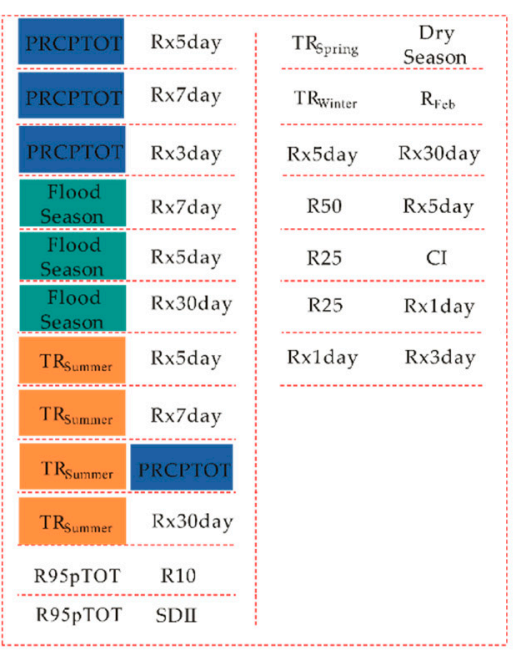

$0.6<$ Correlation Coefficient $<0.75$

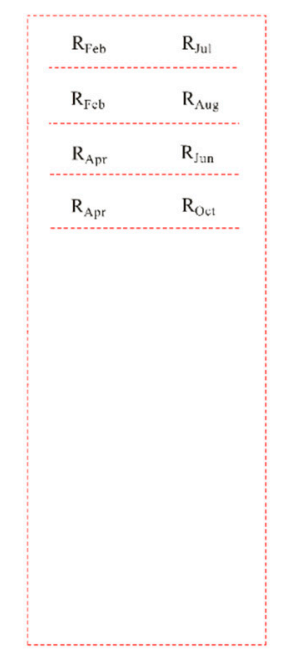

$0.35<$ Correlation Coefficient $<0.6$

Figure 3. The index group of each coefficient interval at Huajialing Station.

\begin{tabular}{|c|c|}
\hline $\begin{array}{l}\text { Flood } \\
\text { Season }\end{array}$ & PRCPTOT \\
\hline $\begin{array}{l}\text { Flood } \\
\text { Season }\end{array}$ & R99pTOT \\
\hline Rx7day & Rx30day \\
\hline Rx7day & Rx3day \\
\hline Rx7day & Rx5day \\
\hline Rx3day & Rx5day \\
\hline R99pTOT & PRCPTOT \\
\hline Rx1day & R50 \\
\hline $\mathrm{TR}_{\mathrm{winter}}$ & $\mathrm{R}_{\mathrm{Fcb}}$ \\
\hline R10 & R95pTOT \\
\hline $\mathrm{R}_{\mathrm{Feb}}$ & $\mathrm{CDD}$ \\
\hline
\end{tabular}

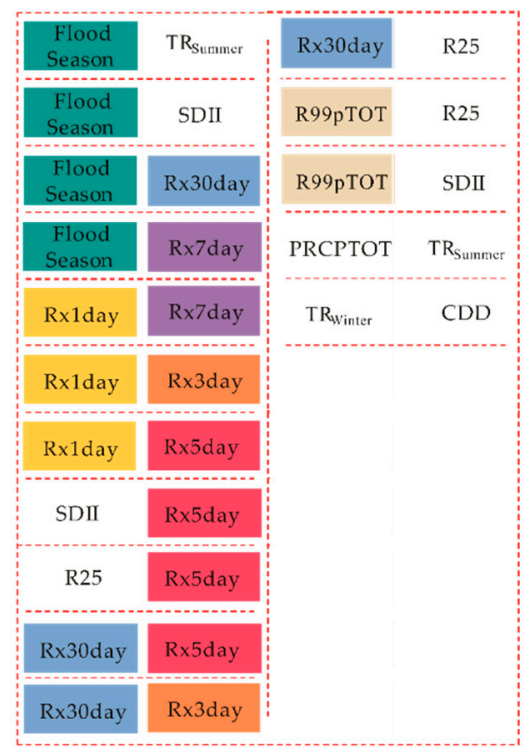

$0.6<$ Correlation Coefficient $<0.75$

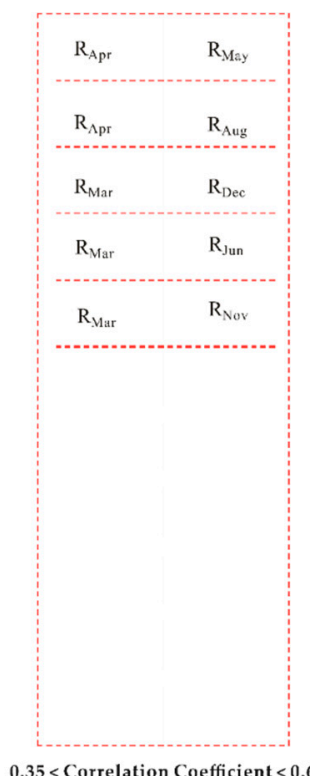

$0.35<$ Correlation Coefficient $<0.6$

Figure 4. The index group of each coefficient interval at Wugong Station. 


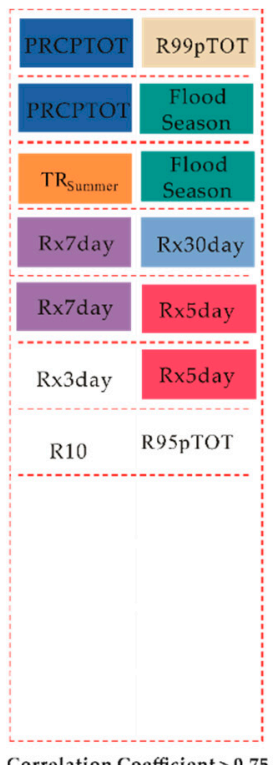

\begin{tabular}{|c|c|c|c|}
\hline RCPTOT & R10 & Rx30day & Rx3day \\
\hline CPT & R25 & Rx7day & Rx3day \\
\hline RCPT & R95pTOT & Rx7day & $\mathrm{TR}_{\text {Summer }}$ \\
\hline PRCPTC & Rx30day & Rx7day & SDII \\
\hline $\begin{array}{l}\text { Flood } \\
\text { Season }\end{array}$ & Rx30day & Rx7day & R50 \\
\hline $\begin{array}{l}\text { Flood } \\
\text { Season }\end{array}$ & R25 & Rx1day & R50 \\
\hline $\begin{array}{l}\text { Flood } \\
\text { Season }\end{array}$ & R95pTOT & Rx5day & Rx3day \\
\hline $\begin{array}{l}\text { Flood } \\
\text { Season }\end{array}$ & R99pTOT & $\mathrm{TR}_{\text {Winter }}$ & $\mathrm{R}_{\mathrm{Feb}}$ \\
\hline R25 & R99pTOT & $T R_{\text {Autumn }}$ & $\mathrm{R}_{\mathrm{Sep}}$ \\
\hline Rx30day & R99pTOT & $\mathrm{TR}_{\text {spring }}$ & $\mathrm{R}_{\mathrm{May}}$ \\
\hline Rx30day & $\mathrm{TR}_{\text {Summer }}$ & & \\
\hline
\end{tabular}

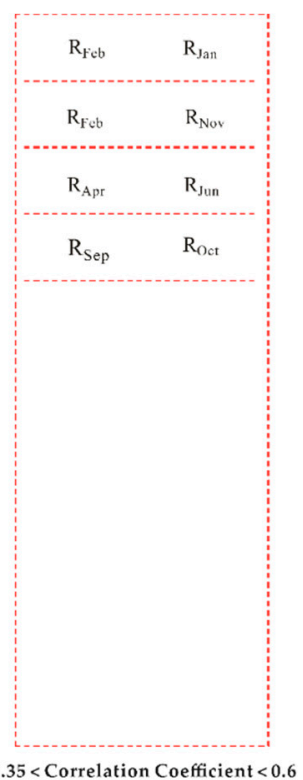

Figure 5. The index group of each coefficient interval at Huashan Station.

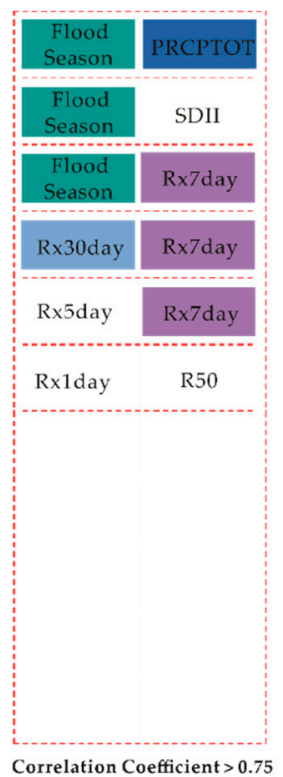

\begin{tabular}{|c|c|c|c|}
\hline RCPTI & R10 & R99pTOT & SDII \\
\hline RCPTO' & R99pTOT & Rx7day & SDII \\
\hline 'RCPTO' & R95pTOT & $R \times 7$ day & Rx3day \\
\hline PRCPTO & NDD & Rx5day & Rx3day \\
\hline PRCPTO & SDII & $\mathrm{CI}$ & Rx1day \\
\hline PRCPTO & Rx30day & $\mathrm{CI}$ & R50 \\
\hline Rx5day & Rx30day & R10 & R95pTOT \\
\hline SDII & Rx30day & $\mathrm{R}_{\text {Sep }}$ & $T R_{\text {Autumn }}$ \\
\hline Rx3day & Rx30day & $\begin{array}{c}\text { Dry } \\
\text { Season }\end{array}$ & $\mathrm{TR}_{\text {Spring }}$ \\
\hline $\begin{array}{c}\text { Flood } \\
\text { Season }\end{array}$ & Rx30day & & \\
\hline $\begin{array}{l}\text { Flood } \\
\text { Season }\end{array}$ & $T R_{\text {Summer }}$ & & \\
\hline
\end{tabular}

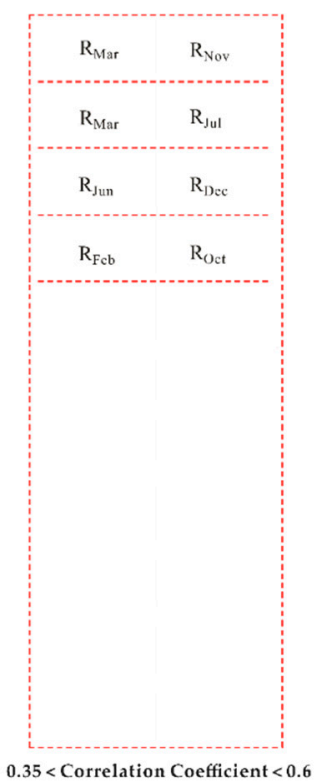

Figure 6. The index group of each coefficient interval at Changwu Station. 


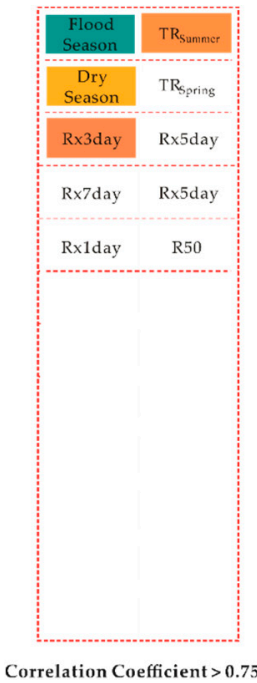

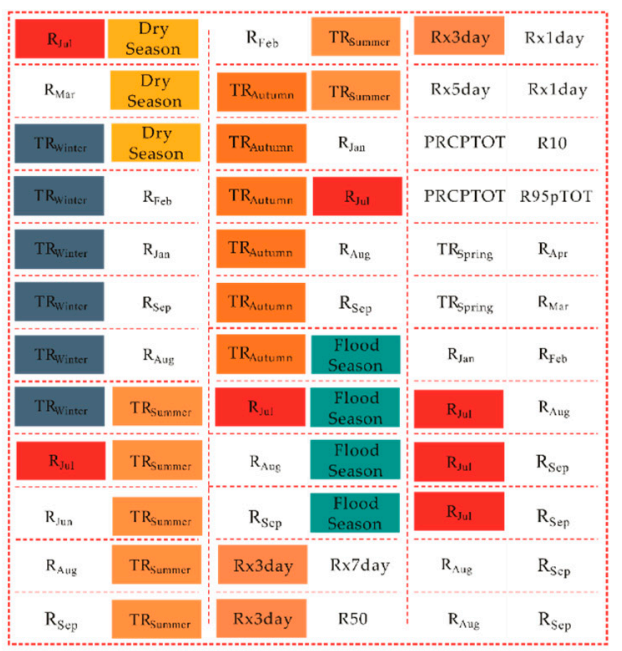

$0.6<$ Correlation Coefficient $<0.75$

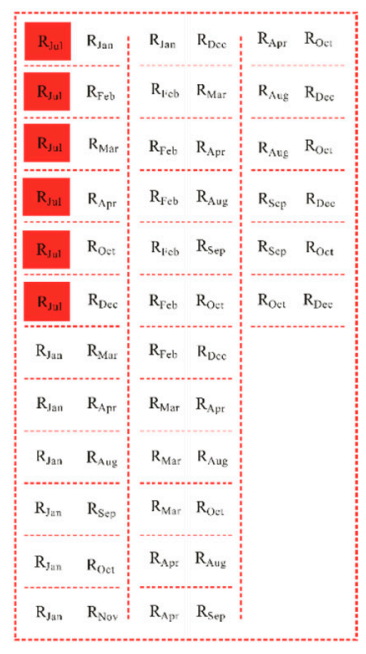

$0.35<$ Correlation Coefficient $<0.6$

Figure 7. The index group of each coefficient interval at Wuqi Station.

In summary, there was spatial differentiation in the correlations of precipitation indexes in the Wei River Basin. The correlations between Dry Season-TR ${ }_{\text {Spring, }}$ Flood Season-TR Summer $_{\text {, }}$ Rx1day-R50, Rx5day- Rx3day-Rx7day were high on the Loess Plateau. R50-Rx1day, Rx7day-Flood Season-Rx30day-Rx5day also had high correlations in the loess tableland area (the region between the Loess Plateau and Guanzhong Plain). On Guanzhong Plain, some paired indexes had high correlations, such as Flood Season-PRCPTOT, Rx5day-Rx3day-Rx7day-Rx30day. The simplification of the index system was carried out according to the principles of representativeness and index structure, and the IPA was as shown in Figure 8. There were 17 indicators in the IPA system, including 9 PSIs, 2 PFIs, and 6 CPIs, as shown in Table 1.

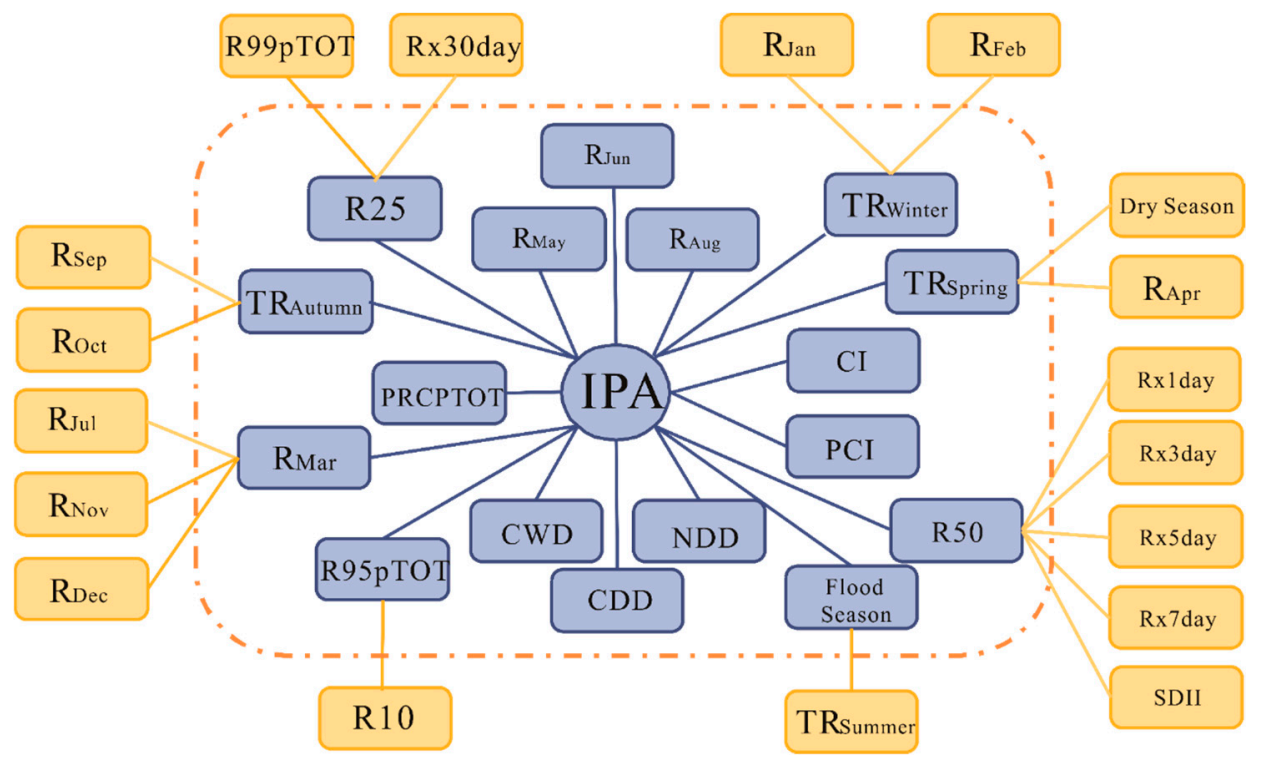

Figure 8. The simplification process of precipitation indexes. The indicators within the dotted line were selected for inclusion in the IPA. 
Table 1. Indexes of precipitation alteration.

\begin{tabular}{cc}
\hline Indicator & Type \\
\hline PRCPTOT & PSI \\
Total Rainfall in Spring $\left(\mathrm{TR}_{\text {Spring }}\right)$ & PSI \\
Total Rainfall in Autumn $\left(\mathrm{TR}_{\text {Autumn }}\right)$ & PSI \\
Total Rainfall in Winter $\left(\mathrm{TR}_{\text {Winter }}\right)$ & PSI \\
Rainfall in March $\left(\mathrm{R}_{\text {Mar }}\right)$ & PSI, PFI (CPI) \\
Rainfall in May $\left(\mathrm{R}_{\text {May }}\right)$ & PSI, PFI (CPI) \\
Rainfall in June $\left(\mathrm{R}_{\text {Jun }}\right)$ & PSI, PFI (CPI) \\
Rainfall in August $\left(\mathrm{R}_{\text {Aug }}\right)$ & PSI \\
Rainfall in Flood Season (Flood Season) & PSI \\
R25 & PSI \\
R50 & PSI \\
R95pTOT & PSI \\
Consecutive Wet Days (CWD) & PFI \\
Consecutive Dry Days (CDD) & PFI \\
Number of Dry Days (NDD) & PSI, PFI (CPI) \\
PCI & PSI, PFI (CPI) \\
CI & PSI, PFI (CPI) \\
\hline
\end{tabular}

\section{Analysis and Discussion}

\subsection{Trend of IPA Indicators Using M-K Trend Test}

The Mann-Kendall trend test was employed to analyze 17 indicators of IPA across five meteorological stations in the Wei River Basin, and the results are shown in Figure 4.

As can be seen from Figure 9, the different indicators varied across the five stations. There were 19 indicators with 95\% significant trend change in the Loess Plateau and the downstream Wei River Basin. For example, at Wuqi Station, $R_{\text {Jun }}, R_{\text {Aug }}, R 50, T R_{\text {Autumn, }}$ and Flood Season had a significant downward trend, and the continuous dry days (CDD) and number of dry days (NDD) increased. This results implies the possibility of long-duration droughts increasing. It was also found that $R_{M a r}$, $\mathrm{TR}_{\text {Winter, }}$, and $\mathrm{TR}_{\text {Spring }}$ had a significant upward trend, indicating that precipitation in winter and spring has increased in recent years. Considering the indicators together, it was found that precipitation has continued to decrease in autumn and to increase significantly in spring and winter on the Loess Plateau. At the same time, it should be noted that rainstorm events have also continued to decrease over the past 60 years, indicating the probability that the occurrence of extreme events will reduce on the Loess Plateau in the future if the existing trend continues.

At Huashan Station in the downstream Wei River Basin, it was seen that the $R_{\text {Aug, }}$ CDD, and NDD showed an increasing trend, while the PRCPTOT, $\mathrm{R}_{\text {Mar }}, \mathrm{R}_{\text {May }}, \mathrm{R} 25, \mathrm{R} 50$, R95pTOT, CWD, TR $\mathrm{R}_{\text {Winter }}$, $\mathrm{TR}_{\text {Spring, }}$ and Flood Season showed a significant decreasing trend. This result indicates that the precipitation amount and extreme precipitation has had a decreasing trend, especially in the spring and winter, and the precipitation indexes related to drought have increased in the downstream Wei River Basin.

In addition, there were not many precipitation indicators with significant trends in the upstream and middle reaches of the Wei River. At Huajialing Station, RCPTOT, $\mathrm{R}_{\text {Aug }}$, R95pTOT, and R50 showed significant decreasing trends, and NDD increased, indicating a trend towards drought and homogenization, and some extreme precipitation events also showed decreasing trends in the upper reaches of the Wei River. At Wugong Station, the $T R_{\text {Winter }}$ had a significant increasing trend and the $\mathrm{CDD}$ and $\mathrm{TR}_{\text {Spring }}$ decreased significantly, implying that a drought in spring should be paid more attention in the middle reaches of the Wei River. Like the above two stations, the precipitation at Changwu Station increased significantly in $\mathrm{TR}_{\text {Winter }}$ and decreasing significantly in $\mathrm{TR}_{\text {Spring. }}$. In terms of spatial distribution, the increase of precipitation in winter and decrease of precipitation in spring was a regional phenomenon and covered the vertical belt of the middle reaches of the Wei River Basin. 


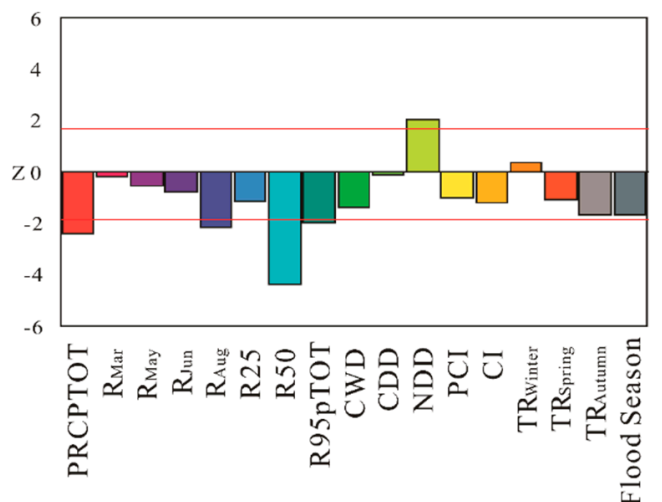

(a) Huajialing

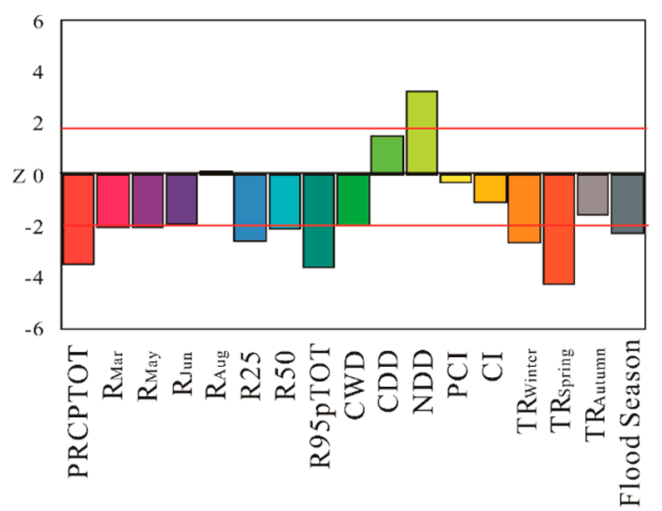

(c) Huashan

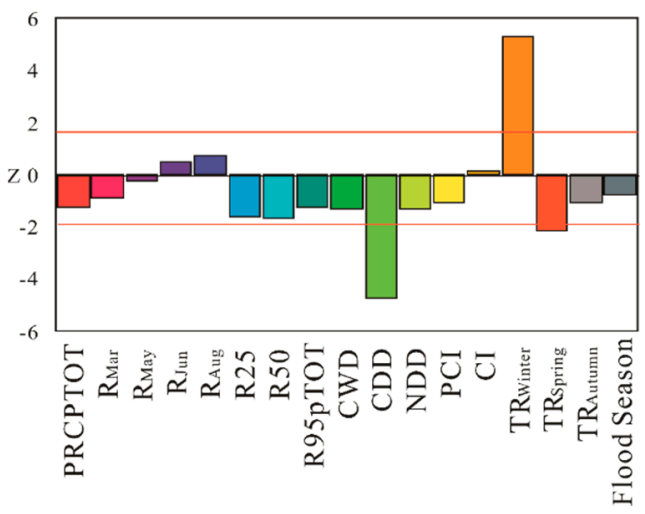

(b) Wugong

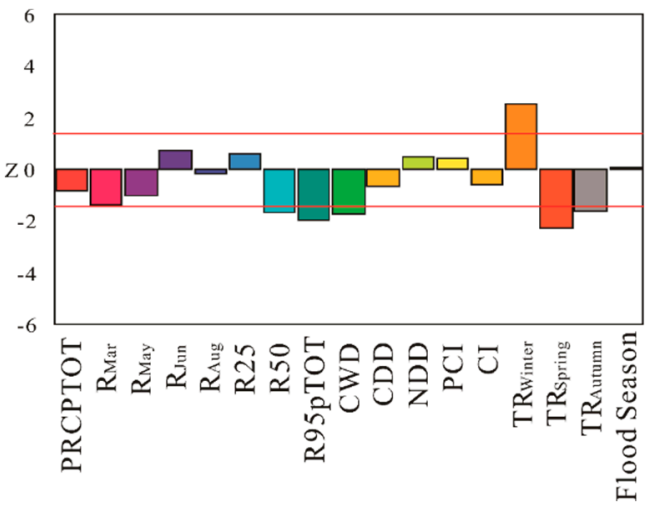

(d) Changwu

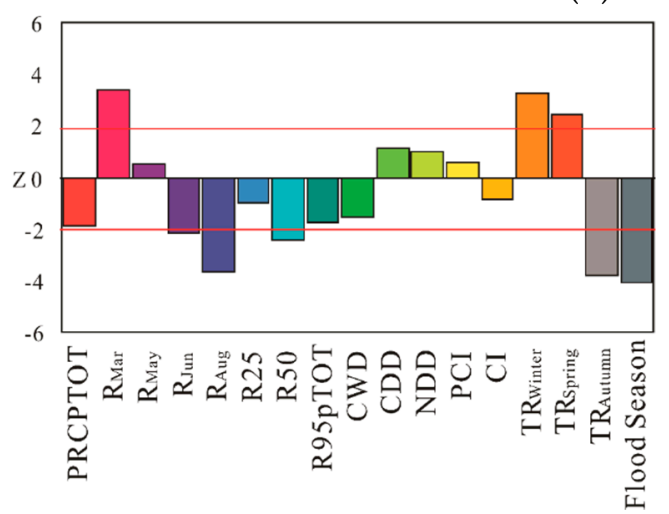

(e) Wuqi

Figure 9. Mann-Kendall trend test result of 17 indicators at five meteorological stations. In the figure, the red line indicates the 95\% significance level. (a) Huajialing, (b) Wugong, (c) Huashan, (d) Changwu, and (e) Wuqi.

In summary, it was found that the indicators at the three stations in the upper, middle, and lower reaches of the Wei River (Huajialing, Wugong, and Huashan Stations, respectively) varied greatly, and the significance of these changes was also varied. Overall, drought trends were identified across the last 60 years, and the key changed area was the lower Wei River Basin. From the precipitation changes at the three stations on the vertical belt (Wugong, Changwu, and Wuqi), the common feature was that precipitation showed a significant increasing trend in winter, and the key altered areas were the middle reaches of the Wei River and the Loess Plateau. Specific results are shown in Table 2. 
Table 2. Trend changes of 17 indicators at the stations (In the figure, $\uparrow$ notes an increasing trend, $\downarrow$ indicating a decreasing trend, and double $\uparrow$ or $\downarrow$ demonstrate significant trends).

\begin{tabular}{|c|c|c|c|c|c|c|}
\hline \multirow{2}{*}{ Station } & \multicolumn{3}{|c|}{ River Direction } & \multicolumn{3}{|c|}{ Vertical Belt } \\
\hline & Huajialing & Wugong & Huashan & Wuqi & Changwu & Wugong \\
\hline PRCPTOT & $\downarrow \downarrow$ & $\downarrow$ & $\downarrow \downarrow$ & $\downarrow$ & $\downarrow$ & $\downarrow$ \\
\hline $\mathrm{R}_{\mathrm{Mar}}$ & $\downarrow$ & $\downarrow$ & $\downarrow \downarrow$ & $\uparrow \uparrow$ & $\downarrow$ & $\downarrow$ \\
\hline $\mathrm{R}_{\text {May }}$ & $\downarrow$ & $\downarrow$ & $\downarrow \downarrow$ & $\uparrow$ & $\downarrow$ & $\downarrow$ \\
\hline $\mathrm{R}_{\text {Jun }}$ & $\downarrow$ & $\uparrow$ & $\downarrow$ & $\downarrow \downarrow$ & $\uparrow$ & $\uparrow$ \\
\hline$R_{\text {Aug }}$ & $\downarrow \downarrow$ & $\uparrow$ & $\uparrow$ & $\downarrow \downarrow$ & $\downarrow$ & $\uparrow$ \\
\hline $\mathrm{R} 25^{\circ}$ & $\downarrow$ & $\downarrow$ & $\downarrow \downarrow$ & $\downarrow$ & $\uparrow$ & $\downarrow$ \\
\hline R50 & $\downarrow \downarrow$ & $\downarrow$ & $\downarrow \downarrow$ & $\downarrow \downarrow$ & $\downarrow$ & $\downarrow$ \\
\hline R95pTOT & $\downarrow \downarrow$ & $\downarrow$ & $\downarrow \downarrow$ & $\downarrow$ & $\downarrow$ & $\downarrow$ \\
\hline CWD & $\downarrow$ & $\downarrow$ & $\downarrow \downarrow$ & $\downarrow$ & $\downarrow$ & $\downarrow$ \\
\hline CDD & $\downarrow$ & $\downarrow \downarrow$ & $\uparrow$ & $\uparrow$ & $\downarrow$ & $\downarrow \downarrow$ \\
\hline NDD & $\uparrow \uparrow$ & $\downarrow$ & $\uparrow \uparrow$ & $\uparrow$ & $\uparrow$ & $\downarrow$ \\
\hline PCI & $\downarrow$ & $\downarrow$ & $\downarrow$ & $\uparrow$ & $\uparrow$ & $\downarrow$ \\
\hline $\mathrm{CI}$ & $\downarrow$ & $\uparrow$ & $\downarrow$ & $\downarrow$ & $\downarrow$ & $\uparrow$ \\
\hline $\mathrm{TR}_{\text {Winter }}$ & $\uparrow$ & $\uparrow \uparrow$ & $\downarrow \downarrow$ & $\uparrow \uparrow$ & $\uparrow \uparrow$ & $\uparrow \uparrow$ \\
\hline $\mathrm{TR}_{\text {Spring }}$ & $\downarrow$ & $\downarrow \downarrow$ & $\downarrow \downarrow$ & $\uparrow \uparrow$ & $\downarrow \downarrow$ & $\downarrow \downarrow$ \\
\hline $\mathrm{TR}_{\text {Autumn }}$ & $\downarrow$ & $\downarrow$ & $\downarrow$ & $\downarrow \downarrow$ & $\downarrow$ & $\downarrow$ \\
\hline Flood Season & $\downarrow$ & $\downarrow$ & $\downarrow \downarrow$ & $\downarrow \downarrow$ & $\uparrow$ & $\downarrow$ \\
\hline $\begin{array}{l}\text { Number of } \\
\text { significantly } \\
\text { changed } \\
\text { indexes }\end{array}$ & 5 & 3 & 11 & 8 & 2 & 3 \\
\hline
\end{tabular}

\subsection{Implication of Functional Indicators}

$\mathrm{R}_{\mathrm{Mar}}, \mathrm{R}_{\mathrm{May}}$, and $\mathrm{R}_{\text {Jun }}$ mainly demonstrate the characteristics of precipitation in spring (Mar-Jun), and their changes describe a great impact on spring irrigation. March is the key period of the rejuvenation-jointing stage of winter wheat; water is critical to winter wheat in this period and its yield will decrease sharply if the water is insufficient. May and June are also the spring irrigation period for cotton, rice, and corn in the Wei River Basin, and the end of the reservoir operation period. At this time, the reservoir storage is nearly empty after several rounds of irrigation, implying that only limited water is available. If there is no precipitation at this time, it is likely to trigger spring drought and cause agricultural losses. If enough precipitation falls, it can effectively increase the water supply to ensure crop yield, combined with spring irrigation. From the changes of the above three indicators, it was found that except for Huashan Station, $\mathrm{R}_{\mathrm{Mar}}, \mathrm{R}_{\mathrm{May}}$, and $\mathrm{R}_{\mathrm{Jun}}$ declined across all stations; the change of $\mathrm{R}_{\mathrm{Mar}}$ at Wuqi Station was the most obvious, indicating that the reduction of spring precipitation in the Wei River Basin is already a regional problem. Although the reducing indicators were different, it is clear that they describe a great impact on the spring drought in the Wei River Basin. It is suggested that an early warning system should be established to monitor spring precipitation, soil moisture, and reservoir water storage to avoid and alleviate spring droughts in the basin.

$\mathrm{CWD}, \mathrm{PCI}$, and $\mathrm{CI}$ are indicators that reflect the probability or frequency of extreme precipitation events. A larger CWD value corresponds to more continuous precipitation days, which increases the risk of water storage projects and can even cause dam failure or downstream flooding and debris flow due to by unreasonable discharge. In addition, the PCI and CI indicators were employed to reflect the concentration of precipitation. The larger the PCI and CI values, the more concentrated the precipitation on a monthly or daily scale, implying that extreme precipitation disasters will be more easily triggered. Focusing on these three indicators, it can be seen that the CWD, PCI and CI values changed very little across different stations. The PCI values for Wuqi and Changwu Stations decreased, indicating that the distribution of precipitation has tended towards uniformity in recent years. However, there were almost no changes in the CWD and CI, indicating that the threat of 
concentrated, continuous precipitation in the short term has not been alleviated, and this should be continuously monitored in the future.

CDD and NDD are indicators that reflect the occurrence probability or frequency of extreme drought events. The greater their values, the greater the drought risk and the more severe of the disaster if does occur. Considering the long-term changes of two indicators, the CDD and NND showed a decreasing trend in the Wei River Basin except for at Wugong Station. In particular, the changes at Huajialing, Wuqi, and Huashan Stations were very significant, indicating that the drought risk in the Wei River Basin has been decreasing. This result was consistent with the SPI evaluation results of previous studies [6]. In terms of space, the indexes of aridification showed an increasing trend from north to south in the transition zone of the Loess Plateau-Guanzhong Plain, and the aridification was significantly decreased in the Loess Plateau, and slightly decreased in the tableland. There was, however, increasing aridification on the Guanzhong Plain, unlike the Loess Plateau and tableland areas.

\subsection{Other Indicators}

Because the R100 had too many zeroes, it was not used in the calculation of MIC in Section 4.2, and was chosen for the IPA. Here, it was taken as an additional factor for analysis. R100 is an extreme precipitation indicator with a low frequency. Once an R100 precipitation event happens, it could trigger big floods and mudslides. The changes of R100 in the Wei River Basin are shown in Figure 5.

From Figure 10a, it can be seen that the frequency of R100 was the highest at Huashan Station, nearly $12 \%$, and was the lowest at Huajialing Station at 0, meaning no R100 event occurred. Spatially, it was found that the R100 in the vertical belt of the Loess Plateau-tableland-Guanzhong Plain (from Wuqi to Changwu and Wugong) showed an increasing trend, which was likely related to the total amount of precipitation in the different areas. Along the Wei River (from Huajialing to Changwu and Huashan), the indicator of R100 presented a greater rising trend than the vertical belt. It is suggested that monitoring, prediction, and warning for extreme precipitation events be strengthened in order to prevent downpour-caused floods and mudslides in the middle and lower reaches of the Wei River.

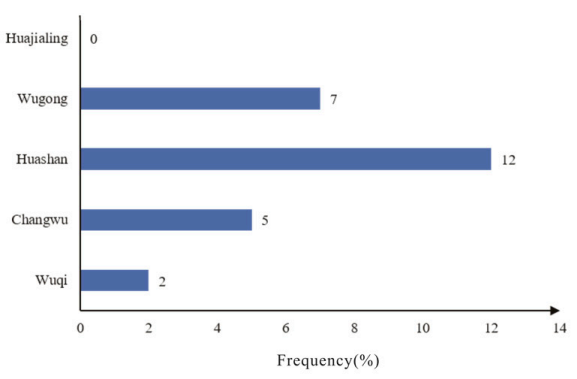

(a)

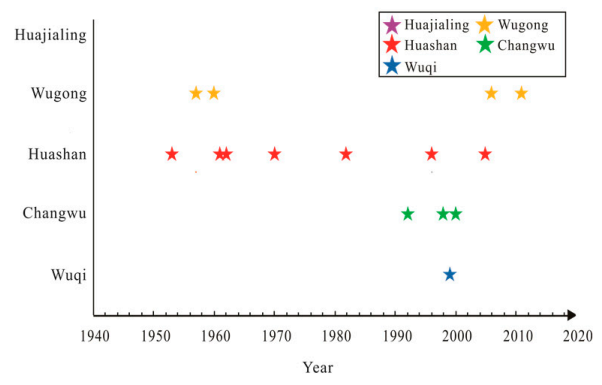

(b)

Figure 10. R100 frequency (a) and time distribution (b) in the Wei River Basin.

Figure 10b shows the occurrences of R100 events across the five stations. From the figure, it can be seen R100 events occurred at four stations besides Huajialing. Through analysis of the occurrence times, it as found that there were two extreme precipitation periods in the time domain in the Wei River Basin. The first period was between 1953 and 1962, in which five R100 events occurred at Wugong and Huashan Stations. The second extreme precipitation period was from 1992 to 2011. Extreme R100 events occurred eight times in total at Wugong, Huashan, Changwu, and Wuqi Stations. Among the stations, Huashan Station had the most frequent occurrence of R100 events, occurring every 10 years on average. More attention should be paid to guarding against downpour-related disasters. In addition, it should be noted that the downpour at Wugong Station presented a 50 year cycle, and two events occurred every time. At Changwu and Wuqi Stations, extreme precipitation events had happened frequently in recent years, representing a change that should be taken into consideration. 


\subsection{Comparison with Other Similar Studies}

To verify the correctness of the results of this index system, we found some relevant literature for comparison. Liu et al. [32] discussed the 1960-2010 CWD and CDD in the Wei River Basin, which were consistent when compared with the indicators used in this study. In addition, the study of precipitation changes by Liu et al. [33] showed a decreasing trend of the total annual rainfall at most precipitation stations in the Yellow River Basin (YRB) in 1961-2006. As an important part of the YRB, the precipitation had a similar change trend in the Wei River Basin. These results are consistent with the calculation results presented in this paper. An article by Zhao et al. [34] discussed the variation of extreme precipitation events through analysis and calculation, and concluded that the extreme precipitation events in the Yellow River Basin are increasing, which is consistent with the IPA results. This comparison with many research results showed that the IPA index was able to accurately evaluate the precipitation characteristics of the Wei River Basin.

\section{Conclusions}

In recent decades, drought and extreme precipitation events have occurred frequently due to population growth and climate change. The quantitative evaluation of precipitation changes and their impact on agricultural production, hydrological cycles, and ecosystems via an index system is particularly important. The prediction of precipitation disasters is complicated and difficult, and the use of precipitation indexes for monitoring is often an important basis for these predictions. Concerning the occurrence of precipitation events in this climatic zone, this study proposed an index (IPA) to evaluate the spatiotemporal trends of precipitation in the study area and to provide useful information for future precipitation assessments. The IPA includes a precipitation structural index (PSI), a precipitation functional index (PFI), and a coupling precipitation index (CPI), which are together able to evaluate the effect of precipitation change on economics, agriculture, and ecology.

In this study, the daily precipitation data of five meteorological stations in the Wei River Basin were analyzed on multiple scales through indicators of precipitation alteration (IPA). The trend changes of the precipitation indexes were evaluated, and the relevant functional influences were discussed. Overall, although the annual total precipitation declined across the five stations, the frequency of extreme events increased, such as the number of days with daily precipitation amount $\geq 100 \mathrm{~mm}$. The specific conclusion drawn are as follows:

(1) The precipitation indictors were chosen from the existing precipitation indexes using the MIC method, and the index system of precipitation alteration (IPA) is established. The index system is suitable for the Wei River Basin and can represent precipitation changes in different landscape areas. The system includes 17 indicators and can cover most features of precipitation, such as pattern, extreme values, duration, distribution, and so on.

(2) It was found that from the analysis of precipitation indexes in the basin that indicators were obviously different at the three stations (Huajialing, Wugong, and Huashan Stations) in the upper, middle, and lower reaches of the Wei River, respectively, and the significantly changed indicators also varied between stations. Overall, from the upstream to downstream of the Wei River, the rainfall showed drought trends in the past 60 years, and the key changed area was the lower Wei River Basin. From the precipitation changes on the vertical belt, the common feature was that precipitation has shown a significant increasing trend in winter, and the key altered areas were middle reaches of the Wei River and the Loess Plateau.

(3) Spatial analysis indicated that the problem of spring precipitation reduction in the basin has been a regional issue. Although the reduced indicators were different, they all had a great impact on spring drought and could trigger disasters. Establishment of an early warning system was suggested, focusing on spring precipitation, soil moisture, and reservoir storage to avoid or alleviate drought events in spring. 
(4) Comprehensive analysis showed a decreasing trend the aridification indexes from north to south in the transition zone of the Loess Plateau-Guanzhong Plain, presenting the most significantly in the Loess Plateau, with a slight reduction in the tableland. In contrast to the northern region, the aridification of Guanzhong Plain was enhanced and could tend towards greater aridification in the future.

(5) The R100 analysis indicated that Huashan Station has had the most frequent occurrence of R100 events, occurring every 10 years on average, and more attention should be paid to guarding against downpour-caused disasters. In addition, downpour at Wugong, Changwu, and Wuqi stations has happened frequently in recent years, representing a change from previous time periods that should be taken into consideration.

Author Contributions: All authors contributed to this study. H.Z.; provided the writing idea, C.L.; carried out data analyses, and wrote the first manuscript draft. X.W. and J.Y. contributed to the analysis of results and drawing. X.G. and H.Z. revised the manuscript and supervised the study. All authors read and approved the final manuscript.

Funding: The current study was jointly supported by the National Natural Science Foundation of China (51979005, 51809005), State Key Laboratory of Eco-hydraulics in Northwest Arid Region, Xi'an University of Technology (2018KFKT-4), and the Water Conservancy Science and Technology Program of Shaanxi Province of China (2018slkj-11).

Conflicts of Interest: The authors declare no conflict of interest.

\section{References}

1. Pecl, G.T.; Araújo, M.B. Biodiversity redistribution under climate change: Impacts on ecosystems and human well-being. Science 2017, 355, eaai9214. [CrossRef] [PubMed]

2. Gaglio, M.; Aschonitis, V. Modelling past, present and future ecosystem services supply in a protected floodplain under land use and climate changes. Ecol. Model. 2019, 403, 23-34. [CrossRef]

3. IPCC Climate Change 2013: The Physical Science Basis; Cambridge University Press: Cambridge, UK, 2013.

4. Longobardi, A.; Buttafuoco, G. Spatial and temporal distribution of precipitation in a Mediterranean area (southern Italy). Environ. Earth Sci. 2016, 75, 189. [CrossRef]

5. Chen, H.P.; Sun, J.Q. Decadal Features of Heavy Rainfall Events in Eastern China. Acta Meteorol. Sin. 2012, 26, 289-303. [CrossRef]

6. Huang, S.Z.; Chang, J.X. Spatio-temporal Changes and Frequency Analysis of Drought in the Wei River Basin, China. Water Resour. Manag. 2014, 28, 3095-3110. [CrossRef]

7. Groisman, P.Y.; Knight, R.W. Contemporary Changes of the Hydrological Cycle over the Contiguous United States: Trends Derived from In Situ Observations. J. Hydrometeorol. 2004, 5, 64-85. [CrossRef]

8. Li, X.M.; Jiang, F.Q. Spatial and temporal variability of precipitation concentration index, concentration degree and concentration period in Xinjiang, China. Int. J. Climatol. 2011, 31, 1679-1693. [CrossRef]

9. Pfahl, S.; Gorman, P.A.O. Understanding the regional pattern of projected future changes in extreme precipitation. Nat. Clim. Chang. 2017, 7, 1-7. [CrossRef]

10. Zhao, W.J.; Yu, X.Y. Analysis of Precipitation Characteristics during 1957-2012 in the Semi-Arid Loess Plateau, China. PLoS ONE 2015, 10, e0141662. [CrossRef]

11. Baettig, M.B.; Wild, M. A climate change index: Where climate change may be most prominent in the 21st century. Geophys. Res. Lett. 2007, 34, L1705. [CrossRef]

12. Asadi Zarch, M.A.; Sivakumar, B. Droughts in a warming climate: A global assessment of Standardized precipitation index (SPI) and Reconnaissance drought index (RDI). J. Hydrol. 2015, 526, 183-195. [CrossRef]

13. Chen, F.L.; Chen, H.M. Annual and seasonal changes in means and extreme events of precipitation and their connection to elevation over Yunnan Province, China. Quat. Int. 2015, 374, 46-61. [CrossRef]

14. Rahmani, V.; Harrington, J. Assessment of climate change for extreme precipitation indices: A case study from the central United States. Int. J. Climatol. 2019, 2, 1013-1025. [CrossRef]

15. Zhang, J.S.; Shen, X.J. Changes in precipitation extremes in Southeastern Tibet, China. Quat. Int. 2015, 380, 49-59. [CrossRef] 
16. Zhang, X.B.; Aguilar, E. Trends in Middle East climate extreme indices from 1950 to 2003. J. Geophys. Res. 2005, 110, D22104. [CrossRef]

17. Griffiths, M.L.; Bradley, R.S. Variations of Twentieth-Century Temperature and Precipitation Extreme Indicators in the Northeast United States. J. Clim. 2007, 20, 5401-5417. [CrossRef]

18. Li, Z.; Zheng, F.L. Spatial distribution and temporal trends of extreme temperature and precipitation events on the Loess Plateau of China during 1961-2007. Quat. Int. 2010, 1, 92-100. [CrossRef]

19. Ren, C.F.; Li, Z.H. Integrated multi-objective stochastic fuzzy programming and AHP method for agricultural water and land optimization allocation under multiple uncertainties. J. Clean. Prod. 2019, 210, 12-24. [CrossRef]

20. Ye, X.; Huang, G.H. Multivariate flood risk analysis for Wei River. Stoch. Environ. Res. Risk Assess. 2017, 31, 225-242. [CrossRef]

21. Yang, J.; Chang, J.X. Comprehensive drought characteristics analysis based on a nonlinear multivariate drought index. J. Hydrol. 2018, 557, 651-667. [CrossRef]

22. Wang, Y.F. Performance Evaluation on Ecological Restoration of Wei River Catchment, Shaanxi Province. Ph.D. Thesis, Northwest A\&F University, Xianyang, China, 2019. (In Chinese).

23. Mann, H.B. Nonparametric tests against trend. Econometrica 1945, 13, 245-259. [CrossRef]

24. Kendall, M.G. Rank correlation methods. Br. J. Psychol. 1990, 25, 86-91. [CrossRef]

25. Xu, M.; Kang, S.C. Detection of spatio-temporal variability of air temperature and precipitation based on long-term meteorological station observations over Tianshan Mountains, Central Asia. Atmos. Res. 2018, 203, 141-163. [CrossRef]

26. Zhang, K.X.; Yao, Y.L. Various characteristics of precipitation concentration index and its cause analysis in China between 1960 and 2016. Int. J. Climatol. 2019, 39, 4648-4658. [CrossRef]

27. Lu, Y.J.; Jiang, S.H. Spatial and Temporal Variability in Precipitation Concentration over Mainland China, 1961-2017. Water 2019, 11, 881. [CrossRef]

28. Martin-Vide, J. Spatial distribution of a daily precipitation concentration index in peninsular Spain. Int. J. Climatol. 2004, 8, 959-971. [CrossRef]

29. Vyshkvarkova, E.; Voskresenskaya, E. Spatial distribution of the daily precipitation concentration index in Southern Russia. Atmos. Res. 2018, 203, 36-43. [CrossRef]

30. Reshef, D.N.; Reshef, Y.A. Detecting Novel Associations in Large Data Sets. Science 2011, 334, $1518-1524$. [CrossRef]

31. Fan, Y.R.; Huang, G.H. Development of PCA-based cluster quantile regression (PCA-CQR) framework for streamflow prediction: Application to the Xiangxi river watershed, China. Appl. Soft Comput. 2017, 51, 280-293. [CrossRef]

32. Liu, S.Y.; Huang, S.Z. Identification of the non-stationarity of extreme precipitation events and correlations with large-scale ocean-atmospheric circulation patterns: A case study in the Wei River Basin, China. J. Hydrol. 2017, 548, 184-195. [CrossRef]

33. Liu, Q.; Yang, Z.F. Spatial and temporal variability of annual precipitation during 1961-2006 in Yellow River Basin, China. J. Hydrol. 2008, 361, 330-338. [CrossRef]

34. Zhao, Y.; Xu, X.D. Trends in observed mean and extreme precipitation within the Yellow River Basin, China. Theor. Appl. Climatol. 2018, 136, 1387-1396. [CrossRef]

(C) 2019 by the authors. Licensee MDPI, Basel, Switzerland. This article is an open access article distributed under the terms and conditions of the Creative Commons Attribution (CC BY) license (http://creativecommons.org/licenses/by/4.0/). 